\title{
Immunoperoxidase technique in histopathology: applications, methods, and controls
}

\author{
EADIE HEYDERMAN
}

\section{From the Department of Morbid Anatomy, St Thomas' Hospital Medical School, London SE1 7EH, UK}

The macroscopic and microscopic morphology of a lesion is the basis of histopathological diagnosis. Conventional 'special' stains are of value in diagnosis but they lack the specificity of immunological reagents. Thus the demonstration of immunoreactive calcitonin in a possible medullary carcinoma of the thyroid is more useful than the demonstration of argyrophilia by a Grimelius stain; similarly, an immunochemical stain for immunoglobulin in plasma cells or lymphomas of B-cell lineage is more conclusive than the pyroninophilia of ribosomal RNA shown by methyl green pyronin. For precise pathological classification we may need to use functional criteria in addition to morphology. Many cell products are readily demonstrable in routinely processed and fixed surgical biopsies, and in material obtained at necropsy, as well as in cryostat sections, smears, monolayer cell cultures, and resin-embedded tissue. The localisation of such cell products has assumed a role of growing importance in routine diagnostic histopathology as well as in research.

\section{Applications}

Tumours produce a wide array of appropriate and inappropriate products including hormones, immunoglobulins, oncofetal antigens, and milk proteins. The localisation of such substances may be of value in diagnosis (Heyderman, 1979), in suggesting a possible primary site for a tumour presenting with metastatic disease, in prognosis, and in suggesting the most suitable circulating marker to be used for individual patient monitoring. Immunocytochemical studies are essential features of the diagnosis of renal disease (Zollinger and Mihatsch, 1978) and of some dermatological disorders (Cooperative Study, 1975). Virus particles (Huang, 1975) and other microorganisms may be visualised by immunocytochemistry not only in their characteristic loci but in previously unsuspected sites, and abnormal storage products such as $a_{1}$-antitrypsin (Blenkinsopp and Haffenden, 1977) may be demonstrated.

Received for publication 26 April 1979
Immunocytochemical methods are available for the demonstration of many of these substances in fixed tissue sections. The permanence of the reaction product together with the facility for simultaneous pathological diagnosis make the immunoperoxidase method the technique of choice in histopathology at the present time (De Lellis et al., 1979).

\section{Methods (Fig. 1)}

The immunoperoxidase technique is an immunological method which may be used for the demonstration of various substances in tissue sections and utilises labelled or unlabelled antibodies and the very stable enzyme, horseradish peroxidase. The most widely used substrate, diaminobenzidine, polymerises in the presence of peroxidase and hydrogen peroxide to form an insoluble brown polymer which is deposited at the site of antigenantibody reaction. Lifting and subsequent loss of tissue sections may be a problem in immunocytochemical studies, especially when multistep methods are used. It is important to cut the sections with a sharp microtome blade and to use a good adhesive such as egg albumin; gelatin in the waterbath is frequently inadequate. The slides are best dried slowly overnight in a $56^{\circ} \mathrm{C}$ oven.

\section{DIRECT METHOD}

The primary antiserum directed against the antigen to be demonstrated is directly labelled with peroxidase. This method is suitable only where antisera are available in reasonable quantity for labelling and as a one-step method is the shortest. It is, however, probably less sensitive than the multiple step methods.

\section{INDIRECT (SANDWICH) METHOD}

(Table) (Figs 2 to 7 )

Here the first antibody is unlabelled and the second antibody, which is directed against the immunoglobulin of the species in which the first antibody is raised, is conjugated to peroxidase (Nakane and 


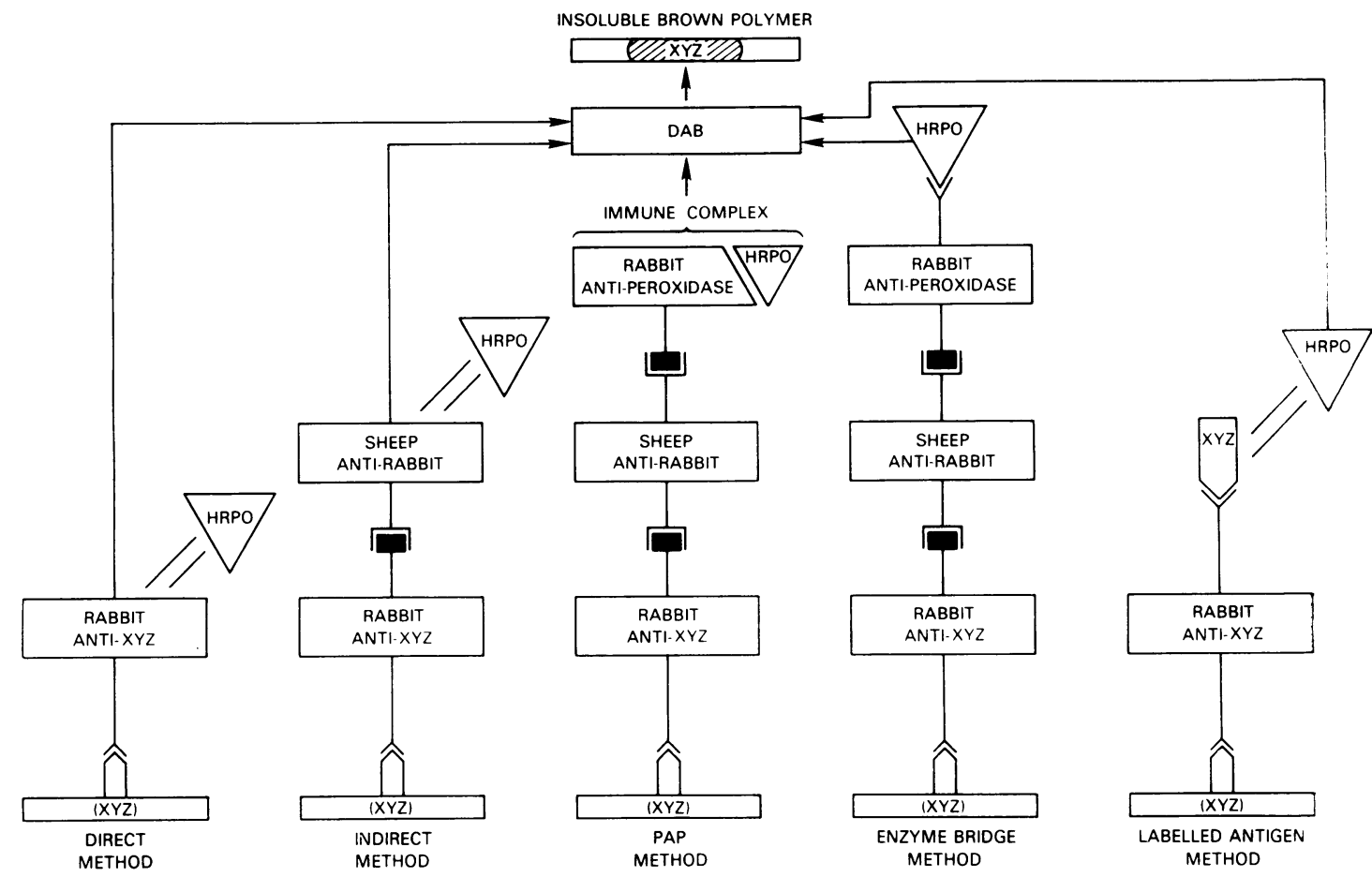

Fig. 1 Immunoperoxidase methods. $X Y Z=$ antigen under test in tissue on microscope slide; $H R P O=$ horseradish peroxidase $; V_{11}=$ conjugate.

Table Immunoperoxidase technique for paraffin-embedded sections

*1 Dewax through xylene and alcohols to water.

2 Bleach acid haematin with $7.5 \% \mathrm{H}_{2} \mathrm{O}_{2}$ in distilled water. Wash off with tap water.

3 Inhibit endogenous peroxidase with $2 \cdot 28 \%$ periodic acid in distilled water. Wash off with tap water.

+4 Block aldehyde groups with $0.02 \%$ potassium borohydride in distilled water. Wash off with tap water. Wash off with PBS (pH 7.2) containing $0.02 \%$ sodium azide.

$\mp 5$ Incubate in moist chamber with $100 \mu \mathrm{l}$ lst antibody diluted in $1 \%$ ovalbumin in PBS. Wash off with PBS.

6 Agitate in PBS bath containing a few drops of detergent (1\% BRIJ 96). (Sigma)

7 Incubate with $100 \mu \mathrm{l} 2$ nd antibody (indirect conjugate) diluted in $1 \%$ ovalbumin in PBS. Wash off with PBS.

8 Agitate in PBS bath containing few drops of detergent (BRIJ).

9 Incubate in diaminobenzidine (DAB) $\left(10 \mathrm{mg}\right.$ DAB freshly dissolved in $10 \mathrm{ml} 0.03 \% \mathrm{H}_{2} \mathrm{O}_{2}$ in PBS). Wash with tap water.

10 Counterstain in Mayer's haemalum; blue in lithium carbonate; dehydrate, clear, and mount in XAM (GURR) or Permount (Fisher).

* For resin-embedded sections remove plastic with saturated alcoholic sodium hydroxide (allowed to mature for five days).

Wash off with absolute ethanol. Wash off with tap water.

+ I have not found that pretreatment with normal serum from the species of animal in which the second antibody (7) was raised improves the results (unpublished data).

$\ddagger$ Conservation of precious antisera or use of low-titre antibodies may be achieved with overnight or 24-hour incubation.

Kawaoi, 1974). The indirect method has advantages over the direct method of increased sensitivity and the small number of peroxidase conjugates requiredone for each species in which antisera are raised. Anti-species antibodies are more readily available in quantity and when affinity purified may be labelled to give excellent results in terms of sensitivity and specificity (Heyderman, 1979).
3 PAP (UNLABELLED ANTIBODY) METHOD The first and second antibodies are unlabelled, and the third reagent is an immune complex of peroxidase-anti-peroxidase precipitated at equivalence (Sternberger et al., 1970). The second antibody acts as a bridge between the first antibody and the anti-peroxidase which is raised in the same species as the first antibody. 


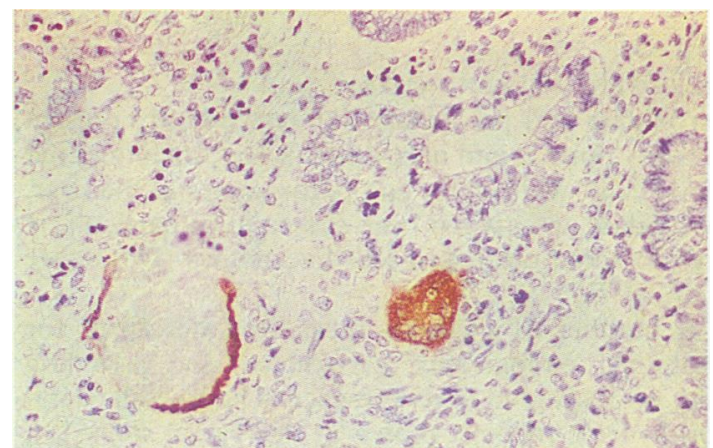

FIG. 2

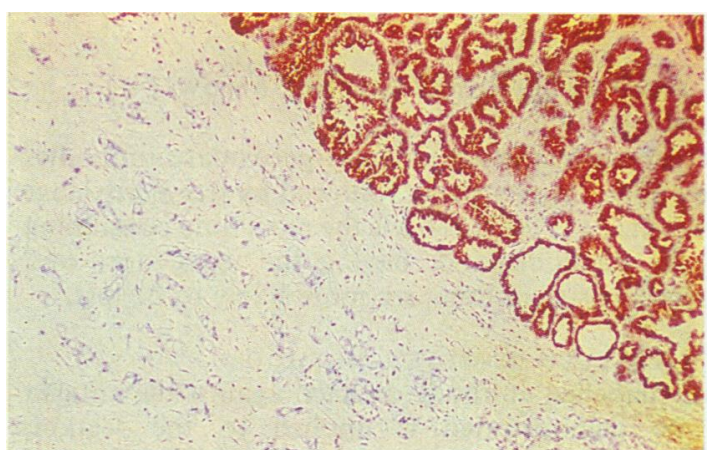

FIG. 3

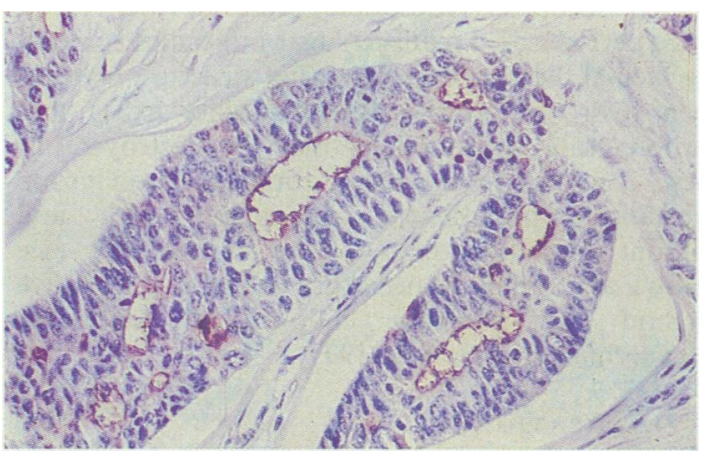

FIG. 4

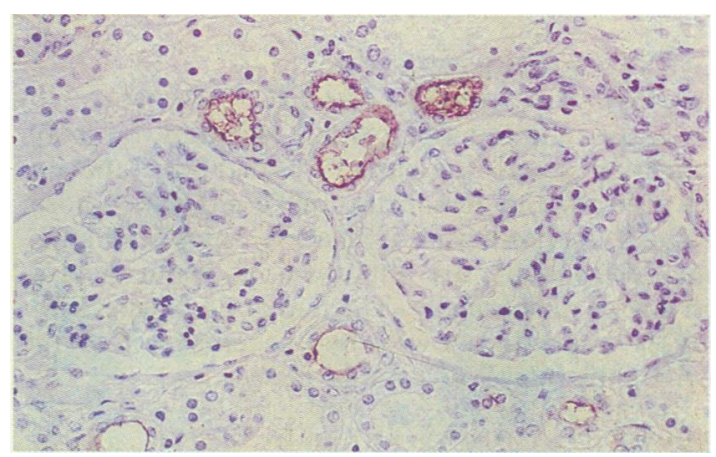

FIG. 5

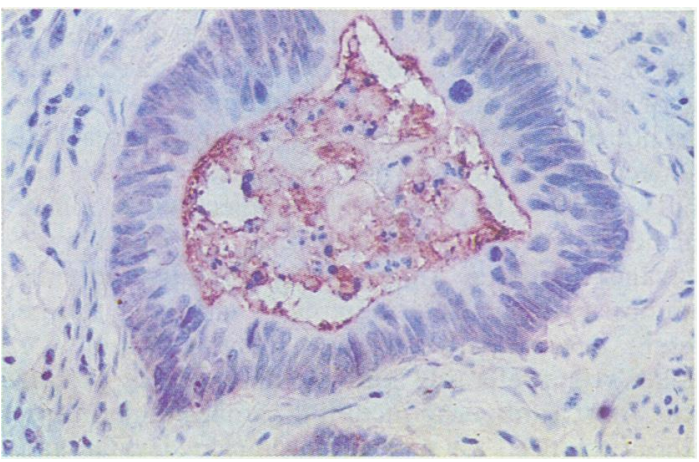

FIG. 6

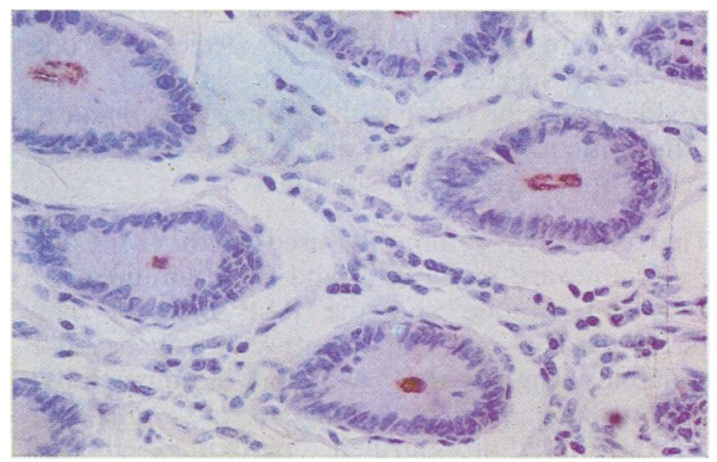

FIG. 7

Examples of wax (Figs 2-5) and resin-embedded (Figs 6 and 7) sections stained by the indirect immunoperoxidase technique.

Fig. 2 Malignant teratoma intermediate stained with antiserum to the specific $\beta$ subunit of HCG. The giant syncytial cell (right) and wall of a vascular channel (left) are positive. Note that endogenous peroxidase in the red cells in the vessel has been completely inhibited. $\times 80$

Fig. 3 Lactational focus in needle biopsy of breast from postpartum patient with infiltrating carcinoma. Stained with antiserum to a lactalbumin. The lactating breast (right) is strongly positive while the milk protein is absent from the carcinoma (left). $\times 32$

Fig. 4 Infiltrating ductal carcinoma of the breast stained with an antiserum to epithelial membrane antigen (EMA). The stain is mainly concentrated on the luminal membrane but there is some cytoplasmic staining. (Reprinted from Journal of Clinical Pathology, 32, 35-39 1979.) $\times 80$

Fig. 5 Non-involved kidney lateral to hypernephroma stained with antiserum to EMA. Only the luminal membrane and casts of the distal tubules are positive. (Reprinted from Journal of Clinical Pathology, 32, 35-39, 1979.) $\times 80$

Fig. 6 Resin-embedded $1 \mu$ section of moderately differentiated adenocarcinoma of the colon stained for CEA.

The luminal membrane of the malignant acini and contained shed cells and debris are positive. $\times 128$

Fig. 7 Resin section of non-involved 'normal' mucosa overlying tumour shown in Figure 5. The luminal membrane of the non-neoplastic glands is strongly positive. $\times 128$ 


\section{ENZYME BRIDGE (TRIPLE SANDWICH) METHOD}

Here the first, second, and anti-peroxidase antibodies are applied sequentially, followed by free peroxidase (Mason et al., 1969). This is the most time-consuming of the methods, and, having the most steps and washes, tissue sections are more likely to be lost.

\section{LABELLED ANTIGEN METHOD}

An unlabelled antibody directed against the antigen to be demonstrated is applied to the section, followed by the antigen which has itself been labelled with peroxidase (Mason and Sammons, 1979). This method is suitable only for materials available in quantity for purification and labelling.

\section{MIXED AGGLUTINATION}

IMMUNOCYTOCHEMICAL (MAGIC) METHOD

This is not an immunoperoxidase technique but may be mentioned here as a variant of method 5 (above). It is used for the demonstration of enzymes whose bioactivity is destroyed by fixation but whose antigenic determinants are retained and should yield a high degree of specificity. The first anti-enzyme antibody is applied followed by the enzyme and its specific substrate (Wachsmuth, 1976).

\section{LOCALISATION BY ENZYMES OTHER THAN PEROXIDASE}

Alkaline phosphatase has been used among others and may be employed in a double labelling technique (Mason and Sammons, 1978). Either the two first antibodies are raised in different species and one second anti-species antibody is labelled with peroxidase and the other with alkaline phosphatase, or the antibodies may be directly labelled. Other enzymes appear to be less suitable.

The two most commonly used methods at the present time are methods 2 and 3 , the indirect or sandwich technique and the PAP method. The latter is used in most laboratories largely because reasonable reagents are available commercially, but, using such commercial reagents and comparing them with affinity-purified peroxidase-labelled second antibodies, I have consistently failed to show increased sensitivity without loss of specificity. In addition, the PAP technique is one stage longer (Heyderman and Neville, 1977).

Many products retain their antigenic determinants after fixation in Bouin's, Zenker's, or formalin solutions, and wax or resin embedding and removal (Heyderman and Monaghan, 1979). The immunoperoxidase method is equally suitable for cryostat sections, smears, and monolayer tissue cultures. These may be grown on glass cover slips for staining or fixed as pellets and routinely embedded and cut.
ENDOGENOUS PEROXIDASE

Peroxidase and peroxidase-like enzymes are present in many normal and neoplastic tissues, including red blood cells, white cells, and peroxisomes in the liver. Peroxidase activity has been shown to be particularly high in some oestrogen-sensitive tissues (Desombre et al., 1975).

A number of methods have been described for inhibiting endogenous peroxidase and avoiding false positives due to its presence. The periodic acidborohydride method shown in the Table, steps 2-4, inhibits the endogenous enzyme even in eosinophils (in which peroxidase is difficult to block) and results in the crisp definition typical of periodic acid treated sections (Heyderman and Neville, 1977). Since periodic acid oxidises sugar molecules containing vicinal diols, opening the ring structure between such hydroxyl groups, the possibility exists that carbohydrate determinants may be destroyed. In these cases, as in the localisation of blood group substances, preliminary experiments with and without inhibition need to be carried out (see below), and it may be necessary to use an alternative method for blocking endogenous peroxidase (Heyderman and Neville, 1977).

\section{TR Y PSINISATION}

There has been much interest recently in the enhancement of immunocytochemical staining by pretreatment of paraffin-embedded formalin-fixed sections with trypsin or other proteolytic enzymes (Huang et al., 1976), particularly for the demonstration of immunoglobulins. The difficulty about the use of such enzymes is that the technique is fickle so that not only is it easy to undertreat or overtreat but the decision on the 'correct' treatment is made on what appears to be purely subjective grounds. Furthermore, the possibility that the proteolytic cleavage of tissue antigens may yield fragments common to many determinants is very real. At the present time a better fixative such as Bouin's or Zenker's is preferable and yields excellent results with most antigens including immunoglobulins, without the need for trypsinisation (Heyderman and Monaghan, 1979; and unpublished observations). If trypsinisation is used, and various times of incubation and temperature, an absorption control at each stage is necessary. My own experience is that the degree of discrimination between strongly positive cells and stroma or overlying epithelium is markedly reduced.

\section{CARCINOGENICITY}

All the chromogenic substrates in present use are best regarded as potentially carcinogenic or toxic and should be treated with extreme caution. They 
should be handled with gloves in a fume cupboard. Manufacturers should be encouraged to market the substrates in convenient injection-type vials so that no weighing or handling of the dry powder is required. The formation of an aerosol during weighing is a particular problem with diaminobenzidine, which is still the best peroxidase substrate for both light and electron microscopy. Fortunately, it is already obtainable ready weighed (BDH, Poole, UK; Polysciences, USA).

\section{Controls}

There is little technical difficulty in staining sections using the immunoperoxidase technique. The problems are the production or acquisition of good antisera and the validation of the results achieved with them. All too often submitted papers show only that the investigator has used differently labelled bottles of antiserum but has offered no evidence that the material demonstrated is really the material under test and not some irrelevant antigen revealed by an unwanted contaminating antibody in one of the reagents.

Monoclonal antibodies produced by hybridomas (Köhler and Milstein, 1976) will have the advantage of being well characterised and eventually available in bulk so that laboratories world-wide can compare results, knowing that the reagents are recognising the same antigenic determinants. Until these reagents are in general use, careful controls in each laboratory, regardless of the source of the antisera, are essential.

\section{ABSORPTION CONTROLS}

The abolition of positive staining after absorption of the antibody with the antigen under test is the most useful specificity control. This can be carried out either by direct addition of the antigen and incubation overnight or better by incubation with antigen coupled to agarose or insolubilised with glutaraldehyde (Avrameas and Ternyck, 1969), so avoiding production of soluble immune complexes which could bind to any $F_{c}$ receptors in the tissue section not destroyed by fixation. Confirmation of the specificity of this loss of activity may be obtained by incubation of the antibody with an unrelated antigen (inappropriate antigen control) and of unrelated non cross-reacting antibodies with the antigen (inappropriate antibody absorption control). These are the controls of choice. Where the antigen is not yet completely characterised (Heyderman et al., 1979) the immunogen or putative antigen may be used for an absorption control. If, as outlined above, it is shown only to absorb out the activity of the antiserum under test, it is a more powerful negative control than normal non-immune serum (see below). As purification of the antigen proceeds, controls can be made more specific. This is not to suggest that the practice of absorbing an antiserum with impure antigen used to raise it is desirable. It could lead to a misleading impression of specificity. Controls are a progressive process, specificity controls becoming more stringent and valuable as chemical purification of the antigen proceeds. Absorption controls using, for example, absorption with whole serum as a control for one circulating plasma protein are obviously of very limited value.

\section{OTHER CONTROLS}

\section{(a) $D A B$ alone}

If endogenous peroxidase is successfully inhibited (chronic myeloid leukaemic blood smears are useful test slides) the use of substrate alone is an unnecessary control unless one is testing a new antibody directed against an antigen which could be sensitive to the periodic acid used for inhibition. In preliminary work on the localisation of blood group substance ' $A$ ', using an antiserum raised in rabbits by Professor Lemieux (Lemieux, 1979) to synthetic ' $A$ ' oligosaccharide, inhibition of endogenous peroxidase was omitted until it could be shown that the antigenic determinants were insensitive to periodate oxidation (Neville and Heyderman, 1979). Interpretation of positivity found both using substrate alone and with the whole immunochemical sequence is difficult. Thus, in the case of the localisation of blood group substances, positive staining could be due both to endogenous peroxidase and to the exogenous peroxidase of the second antibody peroxidase conjugate, binding to specific anti ' $A$ ' serum applied to ' $A$ ' red blood cells. Having inhibited endogenous peroxidase, positive staining of the red cells could now be interpreted as due to the presence of ' $A$ ' substance. This was confirmed by absorption of the antiserum with the synthetic oligosaccharide and consequent loss of staining.

\section{(b) Omission of one or more reagents or substitution with buffer}

These are unconvincing controls and should be required only in very preliminary experiments. Absence of anti-human activity in second or subsequent antibodies is best visualised using wellcharacterised specific first antibodies on tissues containing previously demonstrated antigens. If indirect conjugates are used alone the section should first be washed in a protein solution ( $1 \%$ ovalbumin in PBS) to prevent non-specific binding. 


\section{(c) Non-immune serum}

The use of pre-immune bleeds or unrelated nonimmune sera of the same species as the specific antiserum is hallowed by tradition but is an inadequate negative control. The essence of immunocytochemical controls is the demonstration of specificity. If the non-immune serum is negative and the specific antiserum positive, the only justifiable conclusions are that they are different, that endogenous peroxidase has been inhibited, and that there are no unsuspected anti-human antibodies in the second or subsequent antisera. Absorption controls are necessary to show that the animal into which the immunogen has been injected has 'seen' only the antigen under test and not an impurity, or that it does not already have antibodies that crossreact with human tissues. Non-immune sera may have interesting specificities for human tissues but these are irrelevant to the validation of specificity of the antiserum under test. If, however, pre-immune sera stain human tissues, and this activity cannot be removed by absorption with insolubilised tissue extracts, the animal is unsuitable for raising antisera for immunocytochemistry. The testing of pre-immune bleeds before immunisation would avoid the use of such animals and waste of valuable antigens.

\section{(d) Comparison with other antisera}

Differences in the distribution of staining with two different antisera are evidence of differing specificity, but similarity per se cannot be used as evidence of identity. Cells secrete and store a variety of substances which can be localised morphologically in only a small range of sites. Thus, antisera to a number of membrane antigens may show similar localisation (Heyderman and Monaghan, 1979), but differences in specificity may be shown by examining other tissues, normal and neoplastic.

An epithelial membrane antigen (EMA) (Heyderman et al., 1979) and $\beta_{1}$ pregnancy specific glycoprotein (SP1) (Bohn, 1972) have the same membrane distribution in carcinoma of the colon, but in the placenta EMA is present on the membrane of the fetal villi, while $\mathbf{S P}_{1}$ is present in the syncytiotrophoblast (Horne et al., 1977). The fact that similar results are obtained with antisera from various sources is not in itself a control. Not infrequently the immunogens come from the same primary source or manufacturer, and contaminants that co-purify are likely to be problems in all laboratories (Moss et al., 1978). It is necessary to exercise constant vigilance, and as these problems are reported in the literature suitable controls must be added.

(e) Blocking with antiserum raised in another species It is not possible to say that because staining produced with antisera raised in two different species has the same distribution both antisera are directed against the same antigen (see $(d)$ above). Furthermore, a blocking system using an antiserum raised in another species is an unsatisfactory negative control. The rationale of the system is that if an antiserum raised in a goat to the antigen under test is applied first, it will bind to all the available sites. If then a rabbit antiserum to the same antigen is applied it will not bind, and staining using anti-rabbit conjugate or the PAP sequence will be negative (see Fig. 1).

There are three possible objections: (a) Unless the specificity of one of the antisera is established by an absorption control ((1) above), both could be directed at a common contaminant. (b) Even if both antisera are directed at the same antigen one could be directed at a carbohydrate determinant and the other against a protein moiety of the same molecule, as with CEA (Ormerod, 1978). In this case the antisera raised in different species do not block each other since they bind to different parts of the molecule (unpublished observation). (c) Antisera raised in animals contain a population of antibodies of differing specificities, binding constants, and immunoglobulin subtypes. Differences of this type could make interpretation difficult. Relatively small quantities of 'pure' antigen are required to make an agarose column for absorption controls and the antibody can be eluted and the column used again and again. Absorption controls remain the method of choice.

\section{(f) Radioimmunoassay and immunodiffusion data}

While loss of activity after absorption of specific antibody with antigen in either radioimmunoassay (RIA) or immunodiffusion systems is reassuring, it is not conclusive. The results must be negative within the system and within the limits of sensitivity of the system under test-the immunoperoxidase system.

Provided pure label is used and cross-reacting antibodies are not present, RIA can be carried out in the presence of 'irrelevant' antibodies even though these same antibodies would stain tissue sections with their multiplicity of antigens. Similarly, in the screening of antisera, non-precipitating or very low titre antibodies may be undetectable by immunodiffusion but be quite suitable for immunocytochemistry (Heyderman et al., 1979).

Most commercial antisera are developed for RIA or for immunodiffusion. It is rarely economically feasible for manufacturers to affinity purify their antisera. Though the label on the vial may be taken to indicate that the contained antiserum has activity against the designated antigen, it cannot be taken to indicate that other antibodies are not present. 
Claims of the specificity of antisera based on the difference of distribution of staining, the fact that the antisera came from several commercial differently labelled containers, and that normal non-immune serum produces no staining must be viewed with extreme caution if not scepticism.

\section{POSITIVE CONTROLS}

It is useful to have a 'library' of normal and neoplastic tissues to use as both positive and negative controls and to establish differences in antisera by virtue of differences in staining. In studies on the localisation of a variety of tumour products, I test new antisera on breast, colorectal, renal, bronchial, and lymphoid tumours as well as on placenta and pituitary. All the tumours are selected to include non-involved 'normal' tissue. Once the presence of an antigen in a tissue has been established using appropriate absorption controls, a section of the known positive tissue should be included in each batch of slides to ensure that absence of positive staining is not due to faulty technique.

However, since tumours frequently arise in an area of field change, claims for the localisation of ectopic or inappropriate products using such 'normal' tissues or material from necropsies may be difficult to interpret. For such studies previously normal tissues, blocked in small thin portions and obtained from traumatic or reconstructive surgery, are required. Where death is the terminal event in a protracted illness, anoxia, malnutrition, or cachexia could cause biochemical changes and postmortem autolysis reflected in the apparent localisation of abnormal products.

Immunocytochemical methods are valuable tools in both routine histopathology and research. Meticulous techniques are important, as is critical appraisal of the results achieved. The discrimination should be such that a slide may be read easily by a novice, and the necessity for 'interpretation' of results usually implies unacceptable stromal staining. The use of controls is essential but such controls need to be regularly reviewed as new possible problems are reported in the literature.

I thank Dr Saul W. Rosen and Dr Alan Rabson for their most useful criticism and discussion; Professor Neville for encouragement; my former colleagues at The Ludwig Institute of Cancer Research who were involved in the preparation of many of the reagents and tissues used in these studies; and Ms Peggy Jacobs for expert secretarial assistance.

\section{References}

Avrameas, S., and Ternyck, T. (1969). The cross-linking of proteins with glutaraldehyde and its use for the preparation of immunoadsorbents. Immunochemistry, 6, 53-66.

Blenkinsopp, W. K., and Haffenden, G. P. (1977). Alpha-1-antitrypsin bodies in the liver. Journal of Clinical Pathology, 30, 132-137.

Bohn, H. (1972). Isolierung und Charakterisierung des schwanger-schafts-spezifischen $\beta_{1}$-Glykoproteins. Blut, 24, 292-302.

Cooperative Study (1975). Uses for immunofluorescence tests of skin and sera. Archives of Dermatology, 111, 371-381.

DeLellis, R. A., Sternberger, L. A., Mann, R. B., Banks, P. M., and Nakane, P. K. (1979). Immunoperoxidase technics in diagnostic pathology. American Journal of Clinical Pathology, 71, 483-488.

Desombre, E. R., Anderson, W. A., and Kang, Y. H. (1975). Identification, subcellular localization, and estrogen regulation of peroxidase in 7,12-dimethylbenz (A) anthracene-induced rat mammary tumours. Cancer Research, 35, 172-179.

Heyderman, E. (1979). Immunocytochemistry in cancer diagnosis. The Tenth Pfizer International Symposium. Cancer Assessment and Monitoring. Churchill Livingstone, Edinburgh. (In press.)

Heyderman, E., and Monaghan, P. (1979). Immunoperoxidase reactions in resin embedded sections. Journal of Investigative and Cell Biology, 2, 119-122.

Heyderman, E., and Neville, A. M. (1977). A shorter immunoperoxidase technique for the demonstration of carcinoembryonic antigen and other cell products. Journal of Clinical Pathology, 30, 138-140.

Heyderman, E., Steele, K., and Ormerod, M. G. (1979). A new antigen on the epithelial membrane: its immunoperoxidase localisation in normal and neoplastic tissue. Journal of Clinical Pathology, 32, 35-39.

Horne, C. H. W., Towler, C. M., and Milne, G. D. (1977). Detection of pregnancy specific $\beta_{2}$-glycoprotein in formalin-fixed tissues. Journal of Clinical Pathology, 30, 19-23.

Huang, S. N. (1975). Structural and immunoreactive characteristics of hepatitis B core antigen. American Journal of the Medical Sciences, 270, 131-139.

Huang, S. N., Minassian, H., and More, J. D. (1976). Application of immunofluorescent staining on paraffin sections improved by trypsin digestion. Laboratory Investigation, 35, 383-390.

Köhler, G., and Milstein, C. (1976). Derivation of specific antibody-producing tissue culture and tumor lines by cell fusion. European Journal of Immunology, 6, 511-519.

Lemieux, R. U. (1978). Human blood groups and carbohydrate chemistry. Chemical Society Reviews, 7, 423-425.

Mason, D. Y., and Sammons, R. E. (1978). Alkaline phosphatase and peroxidase for double immunoenzymatic labelling of cellular constituents. Journal of Clinical Pathology, 31, 454-460.

Mason, D. Y., and Sammons, R. E. (1979). The labelled antigen method of immunoenzymatic staining. Journal of Histochemistry and Cytochemistry, 27, 832-840.

Mason, T., Phifer, R., Spicer, S. S., Swallow, R. A., and 
Dreskin, R. B. (1969). An immunoglobulin-enzyme bridge method for localizing tissue antigens. Journal of Histochemistry and Cytochemistry, 17, 563-569.

Moss, J., Ross, P. S., Agosto, G., Birken, S., Canfield, R. E., and Vaughan, M. (1978). Mechanism of action of choleragen and the glycopeptide hormones: is the nicotinamide adenine dinucleotide glycohydrolase activity observed in purified hormone preparations intrinsic to the hormone? Endocrinology, 102, 415-419.

Nakane, P. K., and Kawaoi, A. (1974). Peroxidaselabelled antibody. A new method of conjugation. Journal of Histochemistry and Cytochemistry, 22, 1084-1091.

Neville, A. M., and Heyderman, E. (1979). Tumour markers in human breast cancer. Tumour Markers. Elsevier, North Holland, Amsterdam. (In press.)

Ormerod, M. G. (1978). Antigenic determinants of carcinoembryonic antigen. Scandinavian Journal of
Immunology, 8, Supplement 8, 433-438.

Sternberger, L. A., Hardy, P. H., Jr., Cuculis, J. J., and Meyer, H. G. (1970). The unlabeled antibody enzyme method of immunohistochemistry. Preparation and properties of soluble antigen-antibody complex (horseradish peroxidase-antihorseradish peroxidase) and its use in identification of spirocheies. Journal of Histochemistry and Cytochemistry, 18, 315-333.

Wachsmuth, E. D. (1976). The localisation of enzymes in tissue sections by immunohistochemistry. Conventional antibody and mixed aggregation techniques. Histochemical Journal, 8, 253-270.

Zollinger, H. U., and Mihatsch, M. J. (1978). Renal Pathology in Biopsy. Springer, Berlin and New York.

Requests for reprints to: Dr E. Heyderman, Department of Morbid Anatomy, St Thomas' Hospital Medical School, London SE1 7EH, UK. 